\title{
FAKTOR - FAKTOR YANG MEMPENGARUHI MAHASISWA DALAM PEMILIHAN TEMPAT KERJA MELALUI METODE ANALYTIC HIERARCHY PROCESS (AHP)
}

\author{
E. Salim¹, S. Musdalifah², A. Sahari ${ }^{3}$ \\ 1,2,3Program Studi Matematika Jurusan Matematika \\ Fakultas Matematika dan IImu Pengetahuan Alam Universitas Tadulako \\ Jalan Soekarno-Hatta Km. 9 Palu 94118, Indonesia \\ emil.gilardino.eg@gmail.com, selvymusdalifah@yahoo.com, agus_sh@yahoo.com
}

\begin{abstract}
Work has a very important role in everyday life. Before entering the world of work, students must know what they will face and what they will get. Consideration in the determination of the workplace will require several factors. The purpose of this study is to get the most influential factor in the selection of the workplace through the Analytic Hierarchy Process (AHP) based on priority or ranking. Factor variable used in the study is salary, work environment, job placement and location. Workplace variable used in the research is BadanPerencanaan Pembangunan Daerah, BadanKetahananPangan Daerah, DinasPekerjaanUmum, Bank Indonesia, BadanPusatStatistikdanBadanPemeriksaKeuangan. The result showed that the most influential factor in the selection of students in the workplace based on priority or ranking is salary by $30.6 \%$ and most work places are most influential in the selection of students in the workplace is Bank Indonesia with $23.8 \%$
\end{abstract}

Keywords $\quad$ : AHP, Faktor, Students, Workplace

\section{ABSTRAK}

Pekerjaan mempunyai peranan yang sangat penting di kehidupan sehari-hari. Sebelum memasuki dunia kerja, mahasiswa terlebih dahulu harus mengetahui apa yang akan mereka hadapi dan apa yang akan mereka dapatkan. Pertimbangan dalam penentuan tempat kerja akan membutuhkan beberapa faktor. Tujuan penelitian ini adalah mendapatkan faktor yang paling berpengaruh dalam pemilihan tempat kerja melalui metode Analytic Hierarchy Process (AHP) berdasarkan skala prioritas atau ranking.Variabel faktor yang digunakan dalam penelitian adalah gaji, lingkungan kerja, penempatan dan lokasi kerja. Sedangkan variabel tempat kerja yang digunakan dalam penelitian adalah Badan Perencanaan Pembangunan Daerah, Badan Ketahanan Pangan Daerah, Dinas Pekerjaan Umum, Bank Indonesia, Badan Pusat Statistik dan Badan Pemeriksa Keuangan. Dari hasil penelitian, diperoleh faktor yang paling berpengaruh pada mahasiswa dalam pemilihan tempat kerja berdasarkan skala prioritas atau ranking yaitu gaji dengan bobot $30.6 \%$ dan tempat kerja yang paling yang paling berpengaruh pada mahasiswa dalam pemilihan tempat kerja adalah Bank Indonesia dengan bobot $23.8 \%$.

Kata kunci

: AHP, Faktor, Mahasiswa, Tempat Kerja 


\section{PENDAHULUAN}

Setiap orang pasti ingin mendapatkan pekerjaan yang layak untuk memenuhi kebutuhan hidupnya.Di masa sulit seperti sekarang ini, untuk mendapatkan pekerjaan yang sesuai dan layak bukanlah suatu hal yang mudah.Dibutuhkan kualitas dan kemampuan yang lebih unggul untuk dapat bersaing di dunia kerja. Menurut Sinaga J. (2009), bekerja di sebuah kantor atau dinas umumnya merupakan keinginan sebagian besar mahasiswa yang sedang mencari pekerjaan. Apalagi jika kantor dinas itu terletak di sekitar tempat tinggal.

Keinginan dan kesesuaian minat mahasiswa terhadap memilih tempat kerja disebabkan oleh beberapa faktor. Nitisemito (1996), mengemukakan bahwa untuk meningkatkan semangat dan gairah kerja dilakukan dengan pemberian gaji yang cukup, memperhatikan kebutuhan rohani, menciptakan suasana kerja santai, memperhatikan harga diri, menempatkan karyawan pada posisi yang tepat, memberikan kesempatan untuk maju, memberikan rasa aman untuk masa depan, mengusahakan karyawan memiliki loyalitas, mengajak karyawan berunding, memberikan insentif yang terarah, dan memberikan fasilitas yang menyenangkan.

Analytic Hierarchy Process (AHP) dapat menyelesaikan masalah multikriteria yang kompleks menjadi suatu hirarki. Masalah yang kompleks dapat diartikan bahwa kriteria dari suatu masalah yang begitu banyak (multikriteria), struktur masalah yang belum jelas, ketidakpastian pendapat dari pengambil keputusan, pengambil keputusan lebih dari satu orang, serta ketidakakuratan data yang tersedia. Menurut Saaty (1993), hirarki didefinisikan sebagai suatu representasi dari sebuah permasalahan yang kompleks dalam suatu struktur multi level dimana level pertama adalah tujuan, yang diikuti level faktor, kriteria, sub kriteria, dan seterusnya ke bawah hingga level terakhir dari alternatif. Dengan hirarki, suatu masalah yang kompleks dapat diuraikan ke dalam kelompokkelompoknya yang kemudian diatur menjadi suatu bentuk hirarki sehingga permasalahan akan tampak lebih terstruktur dan sistematis.

Menurut pengamatan penulis, proses selama mengenyam pembelajaran dan pengalaman mengikuti kuliah lapang dalam pengenalan dunia kerja merupakan salah satu pertimbangan dalam menentukan tempat kerja yang diinginkan. Kegiatan dan komunikasi selama proses tersebut akan memunculkan persepsi atau gambaran secara umum terhadap pemilihan tempat kerja.

\section{METODE PENELITIAN}

Data yang digunakan dalam penelitian ini adalah data primer.Data primer diperoleh dari hasil penyebaran kuisioner kepada responden (mahasiswa). 
Adapun yang menjadi populasi dalam penelitian ini adalah seluruh mahasiswa Jurusan Matematika FMIPA UNTAD yang telah menyelesaikan mata kuliah lapang (magang).Dalam pengambilan sampel, ukuran sampel menggunakan rumus Slovin (Umar, 2000:96) sebagai berikut :

$$
n=\frac{N}{1+N e^{2}}
$$

dimana :

$$
\begin{aligned}
& n=\text { jumlah sampel } \\
& N=\text { jumlah populasi } \\
& e=\text { taraf kesalahan } 10 \%
\end{aligned}
$$

Sedangkan untuk prosedur pada penelitian ini adalah :

1.Memulai penelitian.

2.Studi literatur

3.Mengambil data.

4.Menggunakan metode Analiytic Hierarchy Process

(AHP).
5. Hasil dan pembahasan.

6. Menyimpulkan hasil penelitian.

7. Selesai.

\section{HASIL DAN PEMBAHASAN}

\subsection{Hasil Penelitian}

Setelah mendefinisikan masalah yang akan diteliti dan menentukan solusi yang diinginkan kemudian membuat struktur hirarki yang diawali dengan tujuan umum yaitu menentukan bobot dari faktor yang mempengaruhi mahasiswa dalam pemilihan tempat kerja, dilanjutkan dengan kriteria-kriteria yang telah ditentukan dalam menentukan faktor yang mempengaruhi pemilihan tempat kerja dan alternatif yang ingin dirangking. Adapun kriteria yang dimaksud adalah Badan Perencanaan Pembangunan Daerah (Bappeda), Badan Ketahanan Pangan Daerah (BKP-D), Dinas Pekerjaan Umum (PU), Bank Indonesia (BI), Badan Pusat Statistik (BPS) dan Badan Pemeriksa Keuangan (BPK). Sedangkan untuk alternatif adalah :

1. Gaji.

2. Lingkungan Kerja.

3. Penempatan.

4. Lokasi Kerja. 
Adapun gambar struktur hieraki dari permasalahan di atas adalah sebagai berikut :

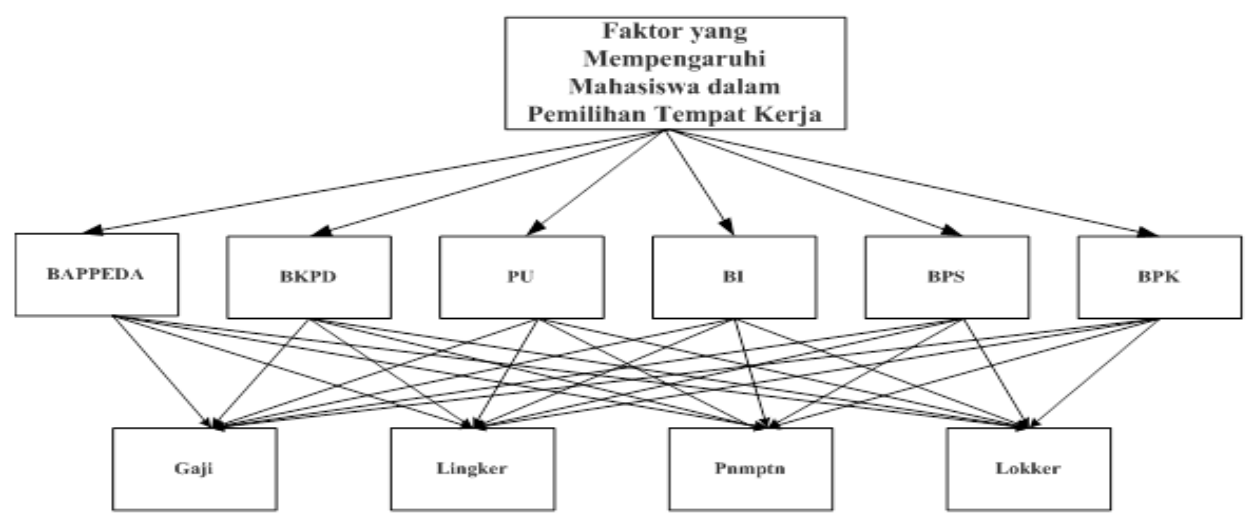

Gambar 1 : Struktur Hirarki Faktor yang mempengaruhi mahasiswa dalam pemilihan tempat kerja

\subsection{Perhitungan Faktor Pembobotan Hierarki Untuk Semua Kriteria}

Berdasarkan hasil perhitungan menggunakan rumus (1) diperoleh jumlah sampel yang akan digunakan sebanyak 43 responden. Adapun Hasil analisis preferensi gabungan dari 43 responden dapat dilihat dari matriks gabungan dibawah ini.

Tabel 1 : Matriks Perbandingan Berpasangan Faktor Pembobotan untuk semua kriteria

\begin{tabular}{|c|c|c|c|c|c|c|}
\hline & BAP & BKP-D & PU & BI & BPS & BPK \\
\hline BAP & 1.000 & 1.359 & 0.935 & 0.666 & 0.798 & 0.816 \\
\hline BKP-D & 0.736 & 1.000 & 0.882 & 0.358 & 0.682 & 0.697 \\
\hline PU & 1.070 & 1.134 & 1.000 & 0.762 & 1.035 & 0.879 \\
\hline BI & 1.501 & 2.794 & 1.312 & 1.000 & 1.516 & 1.156 \\
\hline BPS & 1.253 & 1.466 & 0.966 & 0.659 & 1.000 & 0.902 \\
\hline BPK & 1.225 & 1.435 & 1.137 & 0.865 & 1.109 & 1.000 \\
\hline
\end{tabular}




\subsection{Vektor Eigen dan Vektor Prioritas}

Nilai vektor eigen merupakan bobot setiap elemen. Langkah ini untuk menyelaraskan pilihan dalam penentuan prioritas elemen-elemen pada tingkat hierarki terendah sampaii pencapaian tujuan.

Rumus vektor eigennya, yaitu :

$$
\mathrm{VE}=\sqrt[n]{\prod_{i, j=1}^{n} a_{i j}}
$$

berdasarkan rumus (2), diperoleh masing-masing nilainya adalah 0.991; 0.966; 0.997; 1.036; 1.001; dan 1.010. Dan jumlah nilai vektor eigennya adalah 6.001.

Maka, Rumus Vektor prioritasnya, yaitu :

$$
\mathrm{VP}=\frac{V E}{\sum \sqrt[n]{\Pi_{i, j=1}^{n} a_{i j}}}
$$

berdasarkan rumus (3), diperoleh masing-masing nilainya adalah $0.165 ; 0.161 ; 0.166 ; 0.173$; 0.167 ; dan 0.168 .

\subsection{Evaluasi Inkonsistensi untuk Seluruh Kriteria}

Tabel 2 : Matriks Perbandingan Berpasangan

\begin{tabular}{|c|c|c|c|c|c|c|c|}
\hline & BAP & BKP-D & PU & BI & BPS & BPK & $\begin{array}{c}\text { Faktor } \\
\text { Bobot }\end{array}$ \\
\hline BAP & 0.147 & 0.148 & 0.150 & 0.155 & 0.130 & 0.150 & 0.147 \\
\hline BKP-D & 0.108 & 0.109 & 0.142 & 0.083 & 0.111 & 0.128 & 0.113 \\
\hline PU & 0.158 & 0.123 & 0.160 & 0.177 & 0.169 & 0.161 & 0.158 \\
\hline BI & 0.221 & 0.304 & 0.211 & 0.232 & 0.247 & 0.212 & 0.238 \\
\hline BPS & 0.185 & 0.160 & 0.155 & 0.153 & 0.163 & 0.166 & 0.164 \\
\hline BPK & 0.181 & 0.156 & 0.182 & 0.201 & 0.181 & 0.183 & 0.181 \\
\hline
\end{tabular}

Selanjutnya nilai eigen maksimum ( $\left.\lambda_{\text {maksimum}}\right)$ didapat dengan menjumlahkan hasil perkalian jumlah kolom dengan nilai rata-rata pada matriks yang dinormalisasi. Nilai eigen maksimum yang diperoleh $\lambda_{\text {maks }}=6.039485$. Karena matriks berordo 6 , artinya terdapat 6 kriteria yang dibandingkan maka nilai indeks konsistensi yang diperoleh :

$$
\mathrm{CI}=\frac{\lambda_{\max }-\mathrm{n}}{\mathrm{n}-1}
$$


berdasarkan rumus (4), maka diperoleh $\mathrm{CI}=0.007897$. Untuk $\mathrm{n}=6$ nilai $\mathrm{RI}=1.240$ (tabel Saaty), maka :

$$
\mathrm{CR}=\frac{\mathrm{CI}}{\mathrm{RI}}
$$

berdasarkan rumus (5), maka diperoleh $\mathrm{CR}=0.00636854<0.100$. Karena $\mathrm{CR}<0,100$ berartii preferensi responden adalah konsisten.

\subsection{Faktor Evaluasi untuk Kriteria Badan Perencanaan Pembangunan Daerah (Bappeda)}

Berikut matriks resiprokal hasil preferensi rata-rata dari 43 responden dengan menggunakan rumus rata-rata geometrik untuk kriteria Bappeda:

Tabel 3 : Matriks Evaluasi untuk Kriteria Bappeda yang dinormalkan

\begin{tabular}{|c|c|c|c|c|c|}
\hline & GAJI & LINGKER & PNMPTN & LOKKER & Nilai Rata-rata \\
\hline GAJI & 0.391 & 0.333 & 0.389 & 0.404 & 0.379 \\
\hline LINGKER & 0.286 & 0.243 & 0.353 & 0.120 & 0.251 \\
\hline PNMPTN & 0.177 & 0.121 & 0.176 & 0.325 & 0.200 \\
\hline LOKKER & 0.146 & 0.303 & 0.082 & 0.151 & 0.170 \\
\hline
\end{tabular}

Selanjutnya nilai eigen maksimum ( $\lambda$ maks) didapat dengan menjumlahkan hasil perkalian jumlah kolom dengan nilai rata-rata pada matriks yang dinormalisasi. Nilai eigen maksimum dapat diperoleh $\left(\lambda_{\text {maks }}\right)=4.2679755$. Karena matriks berordo 4 (yakni terdiri dari 4 alternatif), dan berdasarkan rumus (4), maka nilai indeks konsistensinya $(\mathrm{Cl})$ yang diperoleh $\mathrm{CI}=0.0893251666666667$. Untuk $\mathrm{n}=4, \mathrm{RI}=0.900$ (tabel skala Saaty), berdasarkan rumus (5), maka $\mathrm{CR}=0.0992501851851852<0.100$.Karena $\mathrm{CR}<0.100$ berarti preferensi responden adalah konsisten.

\subsection{Faktor Evaluasi untuk Kriteria Badan Ketahanan Pangan Daerah (BKPD)}

Berikut matriks resiprokal hasil preferensi rata-rata dari 43 responden dengan menggunakan rumus rata-rata geometrik untuk kriteria BKPD : 
Tabel 4 : Matriks Faktor Evaluasi untuk Kriteria BKPD yang dinormalkan

\begin{tabular}{|c|c|c|c|c|c|}
\hline & GAJI & LINGKER & PNMPTN & LOKKER & Nilai Rata - Rata \\
\hline GAJI & 0.143 & 0.125 & 0.168 & 0.121 & 0.139 \\
\hline LINGKER & 0.431 & 0.379 & 0.414 & 0.242 & 0.367 \\
\hline PNMPTN & 0.289 & 0.312 & 0.341 & 0.520 & 0.366 \\
\hline LOKKER & 0.138 & 0.183 & 0.077 & 0.117 & 0.129 \\
\hline
\end{tabular}

Selanjutnya nilai eigen maksimum ( $\lambda$ maks) didapat dengan menjumlahkan hasil perkalian jumlah kolom dengan nilai rata-rata pada matriks ternormalisasi. Nilai eigen maksimum dapat diperoleh $\left(\lambda_{\text {maks }}\right)=9.108$. Karena matriks berordo 4 (yakni terdiri dari 4 alternatif) ), dan berdasarkan rumus (4), maka nilai indeks konsistensinya $(\mathrm{Cl})$ yang diperoleh $\mathrm{CI}=0.0386620833333333$. Untuk $\mathrm{n}=4, \mathrm{RI}=0.900$ (tabel skala Saaty), berdasarkan rumus (5), maka $\mathrm{CR}=0.0429578703703704<0.100$. Karena $\mathrm{CR}<0.100$ berarti preferensi responden adalah konsisten.

\subsection{Faktor Evaluasi untuk Kriteria Dinas Pekerjaan Umum (PU)}

Berikut matriks resiprokal hasil preferensi rata-rata dari 43 responden dengan menggunakan rumus rata-rata geometrik untuk kriteria PU.

Tabel 5 : Matriks Faktor Evaluasi untuk Kriteria PU yang dinormalkan

\begin{tabular}{|c|c|c|c|c|c|}
\hline & GAJI & LINGKER & PNMPTN & LOKKER & Nilai Rata-Rata \\
\hline GAJI & 0.305 & 0.389 & 0.325 & 0.161 & 0.295 \\
\hline LINGKER & 0.192 & 0.244 & 0.332 & 0.190 & 0.240 \\
\hline PNMPTN & 0.258 & 0.202 & 0.275 & 0.520 & 0.314 \\
\hline LOKKER & 0.245 & 0.166 & 0.068 & 0.129 & 0.152 \\
\hline
\end{tabular}

Selanjutnya nilai eigen maksimum ( $\lambda$ maks) didapat dengan menjumlahkan hasil perkalian jumlah kolom dengan nilai rata-rata pada matriks ternormalisasi. Nilai eigen 
maksimum dapat diperoleh $\left(\lambda_{\text {maks }}\right)=4.2674615$. Karena matriks berordo 4 (yakni terdiri dari 4 alternatif), dan berdasarkan rumus (4), maka nilai indeks konsistensinya $(\mathrm{Cl})$ yang diperoleh $\mathrm{CI}=0.0891538333333333$. Untuk $\mathrm{n}=4, \mathrm{RI}=0.900$ (tabel skala Saaty), berdasarkan rumus (5), maka $\mathrm{CR}=0.0990598148148148<0.100$, Karena $\mathrm{CR}<0.100$ berarti preferensi responden adalah konsisten.

\subsection{Faktor Evaluasi untuk Kriteria Bank Indonesia (BI)}

Berikut matriks resiprokal hasil preferensi rata-rata dari 43 responden dengan menggunakan rumus rata-rata geometrik untuk kriteria $\mathrm{BI}$ :

Tabel 6 : Matriks Faktor Evaluasi untuk Kriteria BI yang dinormalkan

\begin{tabular}{|c|c|c|c|c|c|}
\hline & GAJI & LINGKER & PNMPTN & LOKKER & Nilai Rata-Rata \\
\hline GAJI & 0.311 & 0.358 & 0.276 & 0.239 & 0.296 \\
\hline LINGKER & 0.304 & 0.350 & 0.415 & 0.345 & 0.353 \\
\hline PNMPTN & 0.284 & 0.213 & 0.252 & 0.339 & 0.272 \\
\hline LOKKER & 0.102 & 0.080 & 0.058 & 0.078 & 0.079 \\
\hline
\end{tabular}

Selanjutnya nilai eigen maksimum ( $\lambda$ maks) didapat dengan menjumlahkan hasil perkalian jumlah kolom dengan nilai rata-rata pada matriks ternormalisasi. Nilai eigen maksimum dapat diperoleh $\left(\lambda_{\text {maks }}\right)=4.060402$. Karena matriks berordo 4 (yakni terdiri dari 4 alternatif), dan berdasarkan rumus (4), maka nilai indeks konsistensinya ( $\mathrm{Cl}$ ) yang diperoleh $\mathrm{CI}=0.020134$. Untuk $\mathrm{n}=4, \mathrm{RI}=0.900$ (tabel skala Saaty), berdasarkan rumus (5), maka $\mathrm{CR}=0.0223711111111111<0.100$. Karena $\mathrm{CR}<0.100$ berarti preferensi responden adalah konsisten.

\subsection{Faktor Evaluasi untuk Kriteria Badan Pusat Statistik (BPS)}

Berikut matriks resiprokal hasil preferensi rata-rata dari gabungan 43 responden menggunakan rumus rata-rata geometrik untuk kriteria BPS : 
Tabel 7 : Matriks Faktor Evaluasi untuk Kriteria BPS yang dinormalkan

\begin{tabular}{|c|c|c|c|c|c|}
\hline & GAJI & LINGKER & PNMPTN & LOKKER & Nilai Rata-Rata \\
\hline GAJI & 0.332 & 0.536 & 0.258 & 0.214 & 0.335 \\
\hline LINGKER & 0.135 & 0.218 & 0.394 & 0.276 & 0.256 \\
\hline PNMPTN & 0.335 & 0.144 & 0.260 & 0.381 & 0.280 \\
\hline LOKKER & 0.198 & 0.101 & 0.0875 & 0.128 & 0.129 \\
\hline
\end{tabular}

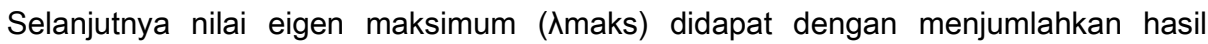
perkalian jumlah kolom dengan nilai rata-rata pada matriks ternormalisasi. Nilai eigen maksimum dapat diperoleh $\left(\lambda_{\text {maks }}\right)=4.25957925$. Karena matriks berordo 4 (yakni terdiri dari 4 alternatif), dan berdasarkan rumus (4), maka nilai indeks konsistensinya $(\mathrm{Cl})$ yang diperoleh $\mathrm{CI}=0.0865264166666667$. Untuk $\mathrm{n}=4, \mathrm{RI}=0.900$ (tabel skala Saaty), berdasarkan rumus (5), maka $\mathrm{CR}=0.096140462962963<0.100$. Karena $\mathrm{CR}<0.100$ berarti preferensi responden adalah konsisten.

\subsection{Faktor Evaluasi untuk Kriteria Badan Pemeriksa Keuangan (BPK)}

Berikut matriks resiprokal hasil preferensi rata-rata dari gabungan 43 responden menggunakan rumus rata-rata geometrik untuk kriteria BPS :

Tabel 8 : Matriks Faktor Evaluasi untuk Kriteria BPK yang dinormalkan

\begin{tabular}{|c|c|c|c|c|c|}
\hline & GAJI & LINGKER & PNMPTN & LOKKER & Nilai Rata-Rata \\
\hline GAJI & 0.359 & 0.489 & 0.255 & 0.279 & 0.346 \\
\hline LINGKER & 0.198 & 0.269 & 0.470 & 0.263 & 0.300 \\
\hline PNMPTN & 0.284 & 0.116 & 0.201 & 0.336 & 0.234 \\
\hline LOKKER & 0.159 & 0.126 & 0.074 & 0.123 & 0.120 \\
\hline
\end{tabular}

Selanjutnya nilai eigen maksimum ( $\lambda$ maks) didapat dengan menjumlahkan hasil perkalian jumlah kolom dengan nilai rata-rata pada matriks ternormalisasi. Nilai eigen maksimum dapat diperoleh $\left(\lambda_{\text {maks }}\right)=4.217536$. Karena matriks berordo 4 (yakni terdiri dari 4 
alternatif), dan berdasarkan rumus (4), maka nilai indeks konsistensinya ( $\mathrm{Cl}$ ) yang diperoleh $\mathrm{CI}=0.072512$. Untuk $\mathrm{n}=4, \mathrm{RI}=0.900$ (tabel skala Saaty), berdasarkan rumus (5), maka $\mathrm{CR}=0.0805688888888889<0.100$. Karena $\mathrm{CR}<0.100$ berarti preferensi responden adalah konsisten.

\subsection{Perhitungan Total Rangking/ Prioritas Global}

Dari seluruh evaluasi yang dilakukan terhadap ke-6 kriteria yakni Badan Perencanaan Pembangunan Daerah (Bappeda), Badan Ketahanan Pangan Daerah (BKP-D), Dinas Pekerjaan Umum (PU), Bank Indonesia (BI), Badan Pusat Statistik (BPS) dan Badan Pemeriksa Keuangan (BPK), yang selanjutnya dikalikan dengan vektor prioritas. Dengan demikian kita peroleh tabell hubungan antara kriteria dengan alternatif.

Tabel 9 : Matriks Faktor Evaluasi untuk Semua Kriteria

\begin{tabular}{|c|c|c|c|c|c|c|}
\hline & Bappeda & BKP-D & PU & BI & BPS & BPK \\
\hline GAJI & 0.379 & 0.139 & 0.295 & 0.296 & 0.335 & 0.346 \\
\hline LINGKER & 0.251 & 0.367 & 0.240 & 0.353 & 0.256 & 0.300 \\
\hline PNMPTN & 0.200 & 0.366 & 0.314 & 0.272 & 0.280 & 0.234 \\
\hline LOKKER & 0.170 & 0.129 & 0.152 & 0.079 & 0.129 & 0.120 \\
\hline
\end{tabular}

Untuk mencari total rangking dari masing-masing variabel faktor-faktor yang mempengaruhii mahasiswa dalam pemilihan tempat kerja adalah dengan cara mengalikan faktor evaluasi masing-masing alternatif dengan faktor bobot, maka diperoleh masing-masing adalah $0.306,0.297,0.273$, dan 0.125 .

Dari hasil diatas diketahui bahwa urutan prioritas dari faktor yang mempengaruhi mahasiswa dalam pemilihan tempat kerja adalah :

Gaji

Lingkungan Kerja

Penempatan

Lokasi Kerja
: $30.6 \%$

: $29.7 \%$

: $27.3 \%$

: $12.5 \%$ 
Dari hasil penelitian didapat faktor yang paling berpengaruh pada mahasiswa dalam pemilihan tempat kerja berdasarkan skala prioritas atau ranking yaitu gaji dengan bobot $30.6 \%$.

\subsection{Pembahasan}

Dari hasil yang diperoleh pada perhitungan kriteria tempat kerja adalah kriteria Bank Indonesia $(\mathrm{BI})$ dengan bobot 0.238 atau $23.8 \%$, kemudian kriteria Badan Pemeriksa Keuangan (BPK) dengan bobot 0.181 atau $18.1 \%$, kemudian kriteria Badan Pusat Statistik (BPS) dengan bobot 0.164 atau $16.4 \%$, selanjutnya kriteria Dinas Pekerjaan Umum (PU) dengan bobot 0.158 atau $15.8 \%$, berikutnya kriteria Badan Perencanaan Pembangunan Daerah (Bappeda) dan kriteria Badan Ketahanan Pangan Daerah (BKP-D) masing-masing dengan bobot 0.147 atau $14.7 \%$ dan 0.113 atau $11.3 \%$.

Untuk Perhitungan alternatif faktor-faktor yang telah ditentukan dimana hasil prioritas yang diperoleh adalah alternatif faktor gaji dengan bobot 0.306 atau $30.6 \%$ sebagai faktor yang paling berpengaruh terhadap pemilihan tempat kerja. Kemudian alternatif lingkungan kerja dengan bobot 0.297 atau $29.7 \%$.Selanjutnya alternatif penempatan dan lokasi kerja dengan bobot masing-masing 0.273 atau $27.3 \%$ dan 0.125 atau $12.5 \%$.

Untuk tempat kerja yang paling berpengaruh pada mahasiswa berdasarkan alternatif faktor prioritas utama yaitu gaji adalah Badan Perencanaan Pembangunan Daerah (Bappeda), Badan Pusat Statistik (BPS) dan Badan Pemeriksa Keuangan (BPK)

\section{KESIMPULAN}

Dari hasil penelitian, diperoleh faktor yang paling berpengaruh pada mahasiswa dalam pemilihan tempat kerja berdasarkan skala prioritas atau ranking yaitu gaji dengan bobot $30.6 \%$, lingkungan kerja dengan bobot 0.297 atau $29.7 \%$, penempatan dan lokasi kerja dengan bobot masing-masing 0.273 atau $27.3 \%$ dan 0.125 atau $12.5 \%$

\section{DAFTAR PUSTAKA}

[1]. Anoraga, P. 1995. "BUMN Swasta dan Koperasl'..PT. Dunia Pustaka Jaya. Jakarta. [2]. Budiarti, L. 2010. Penerapan Efisiensi Kerja Pada Kantor Tata Usaha Fakultas Ekonomi Universitas Sumatera Utara. Fakultas Ekonomi, Universitas Sumatera Utara, Medan. 
[3]. Fewidarto, P.D. 1996. Proses Hirarki Analitik (Analytical Hierarchy Process) Materi Kursus Singkat. Jurusan Tekhnologi Industri Pertanian, Institut Pertanian Bogor. Bogor.

[4]. Mulyono, Sri. 1996. Teori Pengambilan Keputusan. Fakultas Ekonomi Universitas Indonesia, Jakarta.

[5]. Nitisemito, A. S. 1996.., BPFE, Yogyakarta.

[6]. Saaty, T.L. 1993. Proses Hirarki Analitik untuk Pengambilan Keputusan dalam Situasi yang Kompleks.PT Pustaka Binaman Pressindo. Jakarta.

[7]. Sinaga, J. 2009. Penerapan Analytical Hierarchy Process (AHP) Dalam Pemilihan Perusahaan Badan Usaha Milik Negara (BUMN) Sebagai Tempat Kerja Mahasiswa Universitas Sumatera Utara (USU). Universitas Sumatera Utara, Medan.

[8]. Umar, Husein. 2000. Metode Penelitian Untuk Skripsi Dan Tesis Bisnis. PT. Raja Grafindo Persada. Jakarta. 